\section{THE USE OF ASTRINGENTS IN INTESTINAL CATARRH.}

BY (t. C. H. MEIER, M.D., NEW YORK, Instruotor in the Neto York Polyolinic.

WHEN the writer entered the practice of medicine, more than twenty years ago, the treatment of diarrheal affections comprised practically the use of opium, tannic acid, chalk, and bismuth subnitrate. In other words, the chief aim of treatment was to check the profuse diarrheal discharges as soon as possible.

With the development of the doctrine of the bacterial origin of many diseases, the treatment of intestinal disorders underwent a corresponding ehange, and thus arose what might be termed the antiseptic method of treatment. $\Lambda$ large number of antiseptics have been proposed with a view of destroying the pathogenic organisms in the intestinal cinal, and thus preventing fermentative processes. Among those which laive chiefly claimed our attention are salicylic and carbolic acids, creosote, guaiacol-carbonate, resorcin and the various naphtol preparations. I have always been skeptical, however, as to whether the small doses of these drugs that can be andministered with safety are reully able to oxert a sufliciently powerful intiseptic effect to arrest the growth of bacteria in the gastrointestinal tract. 'That they effect some good I am firmly convinced, but $I$ do not think that we should depend upon them completely to the exclusion of other remedial agents.

If we accept the modern theory, that many howel troubles are due to toxic products generated hy bacteria, it seems more logical to me to initiate the treatment of intestinal catarrihs with the use of some evacuant which will promote the elimination of toxins per viam naturalem. 'The drug most useful in my hands for this purpose is calomel, although castor oil may also be employed with good effects. The beneficial influence of cillomel is shown by the chimge in the character of the stools. Castor oil also acts well, especially in the case of children, but is so objectionable to many persons that in most cases I prefer the use of calomel. Having freed the intestinal tract of all toxic irritating material, the diarrheat will sometimes cease under the administration of simple stomachies with bismuth. Often it is neecessiny to resort to further treatment before the profuse and exhausting discharges can be ehecked. Ilere is the proper field for intestinal astringents.

The list of intestinal astringents from which formerly we were compelled to mike our choice wats not a large one, comprising chiefly tamnic acid and various preparations containing it, such as tinctures of kino and cattechu and the mineral astringents, espe-cially acetate of lead, sulphate of zinc, and sulphate of copper. The mineral astringents have the disadvantage of acting as irritants when given in doses sufficient to obtain their plyysiological effect, or of entering into inert combinations in the upper part of the intestinal canal. On the other hand, tamnic acid and the various preparations containing it have the serious objection of irritating the mucous membrane of the stomach by acting upon the albuminous olements, and thus giving rise to more or less gatstric disturbance. Much of the tamnic acid administered probably undergoes alsorption in the upper part of the bowels, or forms insoluble tannates which are devoid of any astringent action. In spite of these disadvantages, tannic acid has always been a favorite intestinal astringent. Lately chemical research has placed in our hands a number of new tannic-acid derivatives in which tannin is presented in a combination which passes unchanged through the stomach, and is gradually and slowly decomposed in the intestinal canal. The first of these preparations, introduced about four years ano to the medical profession, was tamigen or acetyl tamnin. 'This preparation 1 have used quite considerably in my practice, but last year my attention was drawn to tamnopine, a combination of tannin with urotropin, which I believe is superior to the former in many respects.

'T'mnopine contains 87 per cent. of tamnic acid, and owing to its insolubility in fluids of acid or neutral reaction, it passes unchanged through the stomach, thus avoiding the irritating and even canstic effect of tamnin upon the gastric mucosa. In the alkaline Hluids of the intestine, tamnopine is separiated into its constituents, but this decomposition takes place so slowly and gradually that the astringent effect is not confined to the upper parts of the intestinal tract, as with most other remedies of this kind, but extends down to the lower part of the large intestine. Besides its astringent influence, tannopine also exerts an antiseptic action upon the intestinal contents. In my experience, it has never given rise to vomiting or irritition of the digestive tract, and as it is perfectly tasteless, it can be easily administered to children.

1)r. E. Schreiber ${ }^{1}$ is the first to report his observations with tamopine, which were made in Professor Elsstein's clinic in Göttingren. His cases comprised acute and chronic enteritis, tuberculous enteritis, and typhoid fever, and in most instances the results were most encouraging. 'The diarrhea was promptly relieved without the least tendency to constipation. Schreiber warns us, however, not to discontinue the remedy too soon, in order to avoid recurrences. In typhoid fever attended with profuse diarrhea, tamnopine rapidly reduced the number of patssages, which also became firmer in consistence. In tuberculous enteritis it was found necessary to give the drug for a considerable time in order to effect any lasting improvement. In my article published in the New York Medical Jonernal, August 13, 1898, particular attention was directed to the value of tannopine in the chronic forms of diarrhea, especially common in andults and unattended with pain or nausea, the socalled chronic intestinal catarrhs. Excellent results were also obtained in cholerin infintum, gatstro-enteritis and dysentery. Since the publication of my article 1)r. C. Fuchs" hits reported his experience with tamnopine in the medical clinic of Professor Drasche, of Vienna, and expecially comments its action in cases of aceute diarrhen, as weil as in the diarrhea of intestinal tulerculosis. In chronic diarrhear its effect was found to be less certain, for while in some cases it arrested the diarrhea, in others it only diminished the number of evacuations.

Dr. G. Joachim ${ }^{8}$ has particularly tested tamnopine in cases of cholera infantum, cholera morbus and enteritis. In 19 cases of cholera infantum, in which profuse watery evacuations had been present for several days, tamnopine acted very favorably. In 51 cases of gatstro-intestinal catarrh tamopine was ad- 
ministered in connection with minute doses (onetwelfth grain) of calomel, the latter being added for its disinfectant action. Good results were obtained in the majority of cases. In intestinal tuberculosis the results were much less favorable than those recorded by othere authors. Joachim also points out that the remedy must be continued for some days after the cessation of the diarrlea in order to insure permanent cure.

Dr. J. Landaut has treated 79 cases of intestinal affections in children with tamnopine, the majority being acute enteritis and gastro-enteritis, and most of the patients being below two years of age. He observed that under its administration in doses of four to eight grains four or five times a day, the diarrhea promptly subsided without the least disturbance of the digestive tract.

My later experiments with tamopine confirm the results of my former olsservations. I have found it to be even more efficient than tamnigen in intestinal catarrhs, and especially adapted for children, as it is perfectly imnocuous even in large doses. My experience embraces abont 20 cases, and the results were particularly gratifying in the non-inflammatory forms of diarrhea, where the stools were frequent, watery, and passed without pain. Dietetic treatment should always be combined with the administration of tamnopine. All food which is liable to fermentation and to increase the looseness of the bowels should be prohibited; a meit or milk diet should be strictly adhered to for some time, and sweets and pastry absolutely refrained from, as well as malt liguor's and coffee.

Irrigation of the bowels with a warm normal salt solution will be found very grateful to the patient, particuturly where there is some straining at stools, showing an involvement of the rectum. I have found it $a$ good plan in the early stage of any diarrhea to administer a brisk purgative, such as castor oil or frequently repeated small doses of calomel, the latter acting at the same time as a disinfectant to the whole intestinal tract, checking fermentation and acting as a germicide to the bacteria present. Well-ventilated rooms and plenty of outdoor air also exert a favorable influence by their tonic power on the whole system and assist in overcoming the action of the toxins by increasing the vitality of the tissues.

'The following cases taken from' my record book illustrate well the conditions in which tamnopine has proven most valuable in my hands, and will, I trust, be of interest to the reader:

(Ass 1. ('harley 1)., age five years, had been suffering for two days with vomiting and diarrhen, the stools being watery and containing shreds of mucus; no fever was present. He was put on calomel, one grain every hour, and the intestine flushed with sterilized salt water, using about two quarts injected as high up as posssble. 'The vomiting oeased under' this treatment, but the diarrhea cantinued, though with less frequency. Tannopine was now prescribed in eightgrain doses every three hours, and ohocked the discharge in two days, Treatmont was continued for another day to assure a permanenoy of the curo, and the patient has sinoe remained well.

CAsE II. Mrs. Th. M., fifty-nine year's of age, suffers from chronic diarrhea, which makes its appearance whenever she is worried or angry. She is also affected with prolapsus uteri. Opium had a very dis-

\footnotetext{
- Monatosohrift filir praktische Medioin, December, 1898.
}

agreeable after-efiect when given for the diarrhea, so she: was just put on tamopine, ten grains three times "day, which succeeded in checking the discharge after a few closes, leaving no banl after-effects.

CAsv: III. Walker B., age four months, bottlefed, was taken with an acute attack of gastro-enteritis; temperature $104^{\circ}$ (rectal); much pain. The baby was given a cool bath for ten minutes, which reduced the temperature to $101 \frac{1}{2}^{\circ}$. Phenacetin, one grain, was prescribed every three hours, and a dose of castor oil administered. On the following day the child was much improved; the diarrhen, however, continued at intervals. 'Tamopine, three grains, was given every three hours for two days, and the child rapidly recovered.

Case IV. Will 'T., age twelve years, convalescing from an attack of pneumonia, complains of soreness in the abdomen and frequent watery discharges from the bowel. 'Tamnopine, eight grains, was given three times a day, and rapidly effected a cure.

Cast: V. Henry D., age six years, suffers from prolapsus recti, and diarrheal passages. Injections of icc-water were prescribed after each passage, and tamnopine, eight grains, every four hours in a little milk. Bismuth and chalk mixture had been of no avail previously, but tannopine rendered the stools firmer in consistence and kept the diarrhea perfectly in check.

Cass V1. Grace D., age twelve years, complains of headache and diarrhea, which come on on alternate days. She has taken all kinds of diarrheal mixtures, with no permanent benefit. 'The child was ordered to take quinine, three grains, every three hours, and tannopine, five grains, after each stool. Both headache and diarrhea have disappeared. 'The quinine was continued for a week longer, and a few doses of tannopine were given every day. Result, no relapse.

Cask VII. Harry 13, age ten years, was seized suddenly with high fever, vomiting and diarrhea. The stools were slimy, but contained no blood; there was some tenesmus. A dose of castor oil was administered, and followed by five-grain doses of tannopine every three hours. The diarrhea was checked in twenty-four hours, and the passages became normal on the following day.

Cask VIII. Sidney F., age nine months, was suddenly taken with convulsions and an elevation of temperature to $105^{\circ} \mathrm{F}$. He was placed in a cool bath until the temperature was rerluced to $102^{\circ}$. Then he began to vomit and purge; calomel, onefourth grain, was given every half-hour until the discharges became spinach green. Vomiting ceased and tho diarrhea became less frequent. 'Tannopine was now given in doses of three grains every two hours with the result that the stools were speedily changed to a normal consistence. At no time did tannopine produce any nausen or vomiting. It was generally given mixed with subnitrate of bismuth, either in some mucilaginous vehicle or in powders which were taken in milk.

In conclusion I would epitomize my experience as follows :

(1) Thut in all diarrheal affections of recent duration it is of the utmost importance to free the intestinal canal of all irritating material, preferably by the use of small doses of calomel.

(2) After this has been accomplished, it is sually 
necessary to restore the tonicity of the relaxed intestinal mucous membrane and check the discharges by the use of astringents. In diarrheal affections of some days' duration, especially in children, it may be advisable to resort to the use of astringents at once in order to prevent exhaustion and collapse from the profuse and frequent evacuations.

(3) The best form in which to administer an intestinal astringent is one by which the astringent principle is slowly liberated in the intestinal canal so as to nvoid any irritant effect upon the stomach, and also subject the lower intestimal tract to the influence of the remerly.

(4) Tamopine represents an eflicient and reliable intestimal astringent, which, owing to its innocuousness, is well tolerated by the smallest children, and which, while an active astringent, is antirely free from irritating effects upon the intestinal canal.

\section{Clinital gDepartment.}

\section{SYPHILIS AND THE PARASYPHILITIC AFFEC- TIONS: TWO CASES.'}

HY E. W. TAYLOR, M.D., BOSTON.

IT is evident that the last word has by no means been said regarding the etiologrical relationship of syphilis to the so-called parasyphilitic affections. 'Tliat tabes and dementia paralytica occur frequently in persons with an antecerlent syphilitic infection is unquestioned, but we need something more than coincidence to prove the point conclusively. $A$ certain reactionary tendency is visible against the assumption of the close relationship between the two conditions, which has been generally accepted since krb's statistics were published. For example, Guttmann, ${ }^{2}$ in the study of 136 cases, found that 28.6 per cent. had had syphilis and 71.4 had not; six were doubtful. The occurrence of dementia paralytica as a sequence of syphilis is still less constant. It is not our purpose to discuss this diflicult statistical question, but merely to draw attention to the fact that those cases in which there is a co-existence of symptoms of tertiary syphilis and the parasyphilitic affections are of particular clinical interest, and possibly are destined to throw some light on the matter. 'The following cases are also reported because of their somewhat unusual clinical course, and because of the difficulties attending their correct diagnosis.

CAsE I. This patient, W. K., thirty-eight years old, claims to be a Moor, a statement which we have no reason to doubt. He was and is a man of good habits. His occupation formerly was that of a porter in a drawing-room car. In 1891 he was struck on the head in an accident, and from that time claims that he had certain mental peculiarities. He was married in 1890, and very soon thereafter contracted syphilis from his wife; he had a secondary eruption in 1891, was troubled in some way with his eyes, had much sore throat, some pain in the long bones of the legs, but no falling of the hair ; a few months only after these symptoms, distinct delusions of grandeur

1 Kead, In part, at a meeting of the Clinical Section of the Sufrolk Distriot Medical Soclety, March 15, 1890.

2 Gutmann: Tabes Dorealis und Syphilis. Zeltsohr. f. klin. Med. $\times \times \times 7,1898$, p. 242. A bstraot in Journal of Nervous and Mental Dis ease, A ugust, 1899. developed, to which his mother also testitied. He was under the impression that he had twenty-five students; that he was rich; that his mother was going to ('alifornia in a private car. IIe also ordered his house carpeted at an expense of $\$ 500$. He was at this time suspected by his employers of being mentally upset, and in 1893 was committed by Dr. Jelly to the Westhoro Insane Hospital. He had had no definite and vigorous antisyphilitic treatment. Ile remained about six montlıs at Westboro, without special treatment, and at the end of that time was taken home by his wife, who it is said gave him opiates for a period of eight months. Finally, in March, 1894, he was admitted to the Long Island Ilospital, where I first saw him. Ile afterwards said that his memory had entirely failed at that time, that he did not know where he was, and that the first year of his residence at the hospital was practically a blank. During this period, which was before my commection with the hospital, he was unable to walk without assistance and declined absolutely to spenk, but dicl not refuse food. It is probable that he had vague ballucinations of hearing, and at times he had attacks of violence. For several months before making a detailed examination I had observed the patient on my somewhat infrequent visits sitting passively in a chair, making no effort whatever to move, his face indicative of a deep depression, apparently regardless of his surroundings, and perfectly indifferent to his associates. He was being taken daily from his bed to a suil-room, where he spent most of his time, but remained for months perfectly speechless. Attempts to draw him out and elicit a word or two of recognition were alsolutely ineffectual. He seemed depressed beyond the power to rouse, and it was for a time assumed that his refusal to walk was due rather to a mental inhibition than to a physical defect. 'This was, no doubt, in a small measure the case, but further examination revealed more adequate cause. It was as follows :

Motion.-'There was slight tremor of the tongue ; the crinial nerves showed no involvement. There was a much increased reftex at the wrist. The legs were emaciated without giving evidence of true muscular atrophy. Active and passive movements were both very deficient and conducive to spasm in hips and knces. C'omplete extension at the knees was not possible and he could not stand unsupported. The kneejerks were much increased, but true ankle clonus was not obtainable. The gait was extremely spastic.

Sensation. - Muscle sense in the feet and toes retained; no oljective disturbance of sensation. Slight urinary incontinence at night. Subjective complaint of paresthesia of legs.

Eyes. - Pupillary reations normal; complains of a sensation of mist before the eyes, and states that at one time le had double vision.

Speech. - Hesitating in character when finally he began again to speak after being under treatment. The stock expression, "'Third riding regiment of light artillery," was said with great difficulty, and he wats utterly unable to repeat the alphabet spontaneously. The following is one of his attempts: $a, b, o$, $i, c, u, s, t, r, y, z, x, z$, with a tendency to go on indefinitely, and with no adequate consciousness that he was making mistakes.

As already indicated, the mental condition almost at once began to inprove when active treatment of 100 to 200 grains of iodide of potash was instituted. He 